\section{Misdiagnosed normal fetus owing to undetected germinal mosaicism for DMD deletion}

Several cases of germinal mosaicism have been reported in dominantly inherited as well as in $\mathrm{X}$ linked recessive disorders. Proper evaluation of the occurrence of this phenomenon is hindered by the small size of the pedigrees generally studied. It cannot, therefore, be properly taken into account for risk calculation. Instances of germinal mosaicism have been elucidated in Duchenne muscular dystrophy (DMD) families on the basis of more than one affected offspring born to an apparently non-carrier parent. $^{2} 3$ In these families, prenatal diagnosis had not been performed before germinal mosaicism was discovered by RFLP analysis.

We wish to report on one DMD family in which subject I.2, the mother and grandmother of three affected boys, was labelled as an obligate carrier (fig 1). RFLP analysis was performed to determine the carrier status of her daughters. Informative probes exploring the $5^{\prime}$ end of the gene and its flanking regions showed that II.2, II.5, and

Received for publication 23 May 1989. Accepted for publication 6 June 1989.
Journal of Medical Genetics 1989, 26, 790-792

II.6 had inherited the haplotype associated with DMD and had high carrier risks. The carrier status of daughter II.4 was ambiguous, since a recombinational event was found in the 3 ' region of the gene. With the few genomic probes available at the time, no deletion had been detected in the surviving affected boy (III.2). Prenatal diagnosis was first requested by the youngest daughter (II.6) in January 1987. She elected to terminate the pregnancy since her male fetus had the haplotype associated with DMD with a high risk of being affected (fig 1).

As the cDNA probes became available in 1988 , we systematically screened all our DMD patients. A deletion was found in patient III.2, located in the median half of the gene (cDNA probe 44.1) ${ }^{2}$ This part of the gene had been studied with the closest genomic probe available (probe P20); no deletion had been found and his grandmother (I.2) was not informative. Unexpectedly, this deletion was not found in the fetus (III.3) for whom prenatal diagnosis had been requested a year before. All family members were then studied with this probe, which also detects a TaqI polymorphism (fig 2). Patient III.2 was deleted for all constant and polymorphic fragments, whereas his grandmother appeared homozygous. This was ascertained directly by densitometric scanning. Moreover, since all hero daughters, except the mother (II.3) of the DMD boy, were heterozygous for this marker, it could be inferred that the TaqI $6.8 \mathrm{~kb}$ allele belonged to the haplotype associated.

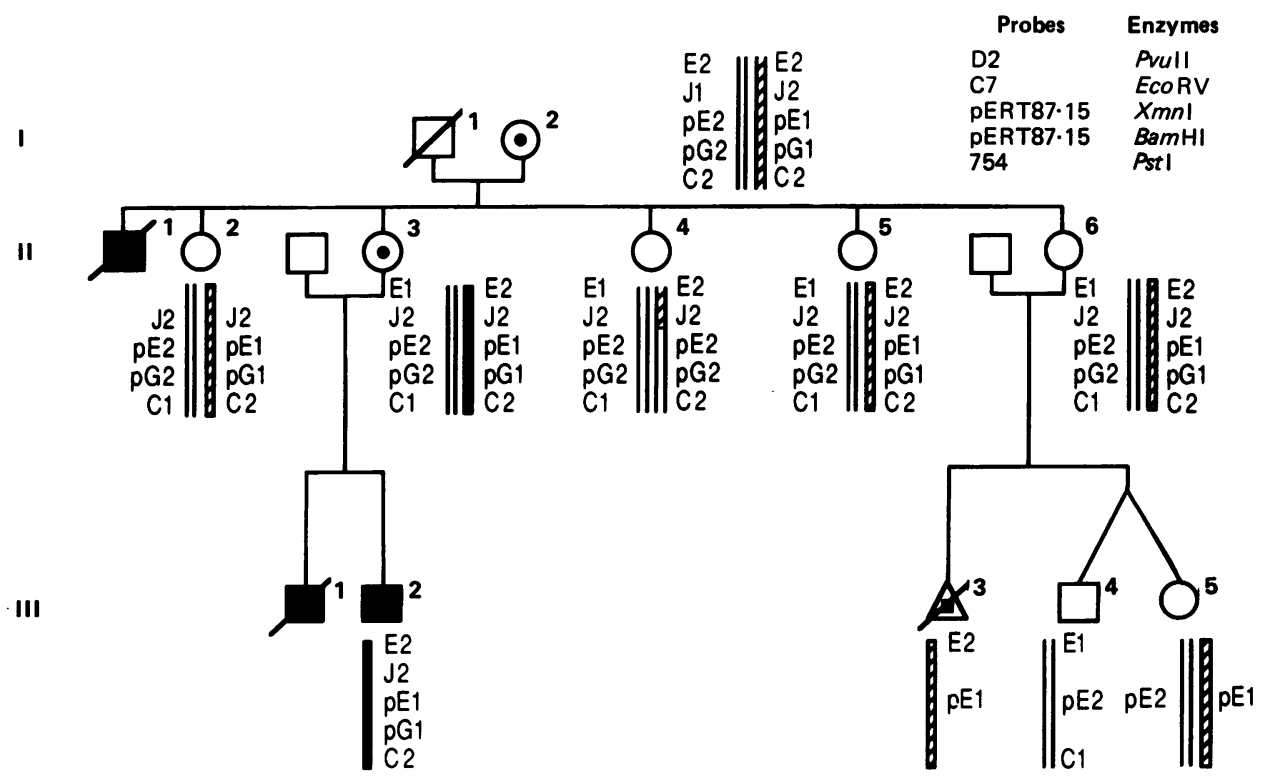

FIG 1 Pedigree and RFLP analysis using genomic probes. Distinct haplotypes are represented by white (paternal haplotypes), black (DMD associated haplotype), and hatched (non-deleted maternal haplotype) bars. I.2 and II.3 are shown as obligate carriers (dots) since they have had at least one child with DMD. 


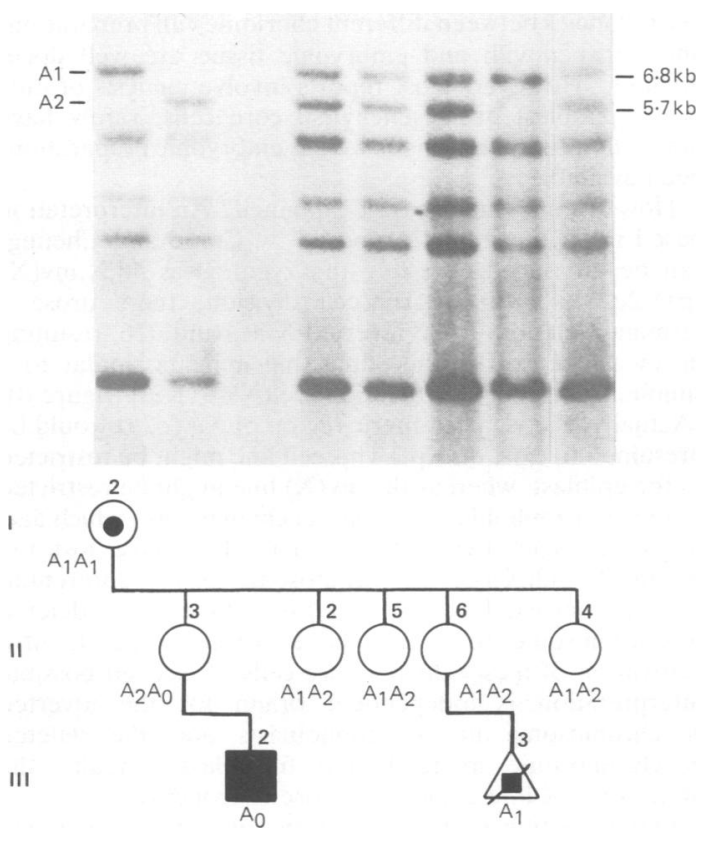

FIG 2 Southern blot of genomic DNA of members of the family digested with TaqI and probed with $c D N A$ subclone 44.1. This probe detects two allelic bands: $6 \cdot 8 \mathrm{~kb}\left(A_{1}\right)$ and $5.7 \mathrm{~kb}\left(A_{2}\right)$ as well as four constant bands $(4 \cdot 8,3 \cdot 9,3 \cdot 5$, and $2 \cdot 5 \mathrm{~kb})$.

with DMD, and that subject I.2 had transmitted three types of gametes: (1) one bearing the deletion (II.3); (2) one non-deleted and non-recombined (II.2, II.5, II.6); (3) one recombined but non-deleted (II.4). These results show that II.4 (in spite of the intragenic recombination), II.2, II.5, and II.6 are in fact not carriers and therefore the prenatal diagnosis performed in 1987 for II.6 misdiagnosed a normal male fetus (III.3).

This is the first case report of erroneous prenatal diagnosis owing to germinal mosaicism overlooked by genomic probes: carrier status had been evaluated with $5^{\prime}$ informative markers, whereas the DMD mutation was located towards the $3^{\prime}$ end of the gene. This stresses the importance of systematically searching for a DMD associated deletion. In these families all potential carriers should be re-evaluated regardless of previous results, using informative markers or densitometric scanning to investigate the deleted region. Our results also stress that germinal mosaicism must be looked for not only in families with an ascertained de novo mutation but also in those presenting as straightforward familial cases.

We wish to thank I Dehaupas, M Coulon, and P Cohen for excellent technical assistance and Dr J Boué for obtaining pedigree data and referring the family.

\section{Bolleau and C Junien INSERM U73, Château de Longchamp, Bois de Boulogne, 75016 Paris; and Laboratoire Central de Biochimie et de Génétique Moleculaire, Hôpital Ambroise Paré, 92104 Boulogne Cedex, France.}

References

' Hall JG. Review and hypothesis: somatic mosaicism: observations related to clinical genetics. Am J Hum Genet 1988;43: $355-63$.

2 Darras BT, Blattner P, Harper JF, et al. Intragenic deletions in 21 Duchenne muscular dystrophy (DMD)/Becker muscular dystrophy (BMD) families studied with the dystrophin cDNA: location of breakpoints on Hind III and Bgl II exon-containing fragment maps, meiotic and mitotic origin of the mutations. Am J Hum Genet 1988;43:620-9.

${ }^{3}$ Wood S, McGillivray BC. Germinal mosaicism in Duchenne muscular dystrophy. Hum Genet 1988;78:282-4.

Correspondence to Professor C Junien, INSERM, Unité 73, Génétique et Pathologie Foetale, Château de Longchamp, Bois de Boulogne, 75016 Paris, France.

\section{Three different, non-mosaic sex chromosome abnormalities (direct cytotrophoblasts, mesenchymal core cultures, and abortus skin fibroblasts): implications for elucidating chorionic villi mosaicism}

A 39 year old Caucasian woman (G2P1001) desired chorionic villus sampling (CVS) because of her age. Her only previous pregnancy resulted in the delivery of a healthy boy $(2780 \mathrm{~g})$ after a 39 week gestation. Her past medical history was unremarkable; no family members had had congenital malformations or spontaneous abortions. During this pregnancy she reported no exposure to toxins or radiation. The father of the fetus was 41 years old, in good health, and had no family members with anomalies.

Ultrasound examination showed a single intrauterine conception consistent with menstrual dates (crown-rump length $44 \mathrm{~mm}$, corresponding to 50 th centile for 11.4 weeks' gestation). No anomalies were seen. Transabdominal CVS was performed without difficulty, yielding $20 \mathrm{mg}$ of chorionic villi. In accordance with our routine, ${ }^{1}$ cleansed villi were incubated overnight in alpha-MEM supplemented with $15 \%$ Chang medium, $15 \%$ fetal bovine serum, and final concentrations of $0.8 \%$ L-glutamine, $100 \mathrm{IU} / \mathrm{ml}$ penicillin, and $100 \mu \mathrm{g} / \mathrm{ml}$ streptomycin. Each of 25 metaphases analysed from cytotrophoblasts contained 44 autosomes, one normal $X$ chromosome, and one abnormal, nearly acrocentric, chromosome (figure a), which appeared to be an inverted X chromosome. Each of

Received for publication 20 April 1989. Accepted for publication 1 June 1989. 